\title{
Second-generation colon capsule endoscopy compared with colonoscopy
}

Cristiano Spada, MD, Cesare Hassan, MD, PhD, Miguel Munoz-Navas, MD, PhD, Horst Neuhaus, MD, Jacques Deviere, MD, PhD, Paul Fockens, MD, PhD, FASGE, Emmanuel Coron, MD, PhD, Gerard Gay, MD, Ervin Toth, MD, PhD, Maria Elena Riccioni, MD, PhD, Cristina Carretero, MD, Jean P. Charton, MD, Andrè Van Gossum, MD, PhD, Carolien A. Wientjes, MD, Sylvie Sacher-Huvelin, MD, Michel Delvaux, MD, PhD, Artur Nemeth, MD, Lucio Petruzziello, MD, Cesar Prieto de Frias, MD, Rupert Mayershofer, MD, Leila Aminejab, MD, Evelien Dekker, MD, PhD, Jean-Paul Galmiche, MD, FRCP, Muriel Frederic, MD, Gabriele Wurm Johansson, MD, PhD, Paola Cesaro, MD, Guido Costamagna, MD, FACG

Rome, Italy; Pamplona, Spain; Düsseldorf, Germany; Brussels, Belgium; Amsterdam, The Netherlands; Nancy, France; Malmá, Sweden

Background. Colon capsule endoscopy (CCE) represents a noninvasive technology that allows visualization of the colon without requiring sedation and air insufflation. A second-generation colon capsule endoscopy system (PillCam Colon 2) (CCE-2) was developed to increase sensitivity for colorectal polyp detection compared with the firstgeneration system.

Objective. To assess the feasibility, accuracy, and safety of CCE-2 in a head-to-head comparison with colonoscopy.

Design and Setting. Prospective, multicenter trial including 8 European sites.

Patients: This study involved 117 patients (mean age 60 years). Data from 109 patients were analyzed.

Intervention. CCE-2 was prospectively compared with conventional colonoscopy as the criterion standard for the detection of colorectal polyps that are $\geq 6 \mathrm{~mm}$ or masses in a cohort of patients at average or increased risk of colorectal neoplasia. Colonoscopy was independently performed within 10 hours after capsule ingestion or on the next day. Main Outcome Measurements. CCE-2 sensitivity and specificity for detecting patients with polyps $\geq 6 \mathrm{~mm}$ and $\geq 10 \mathrm{~mm}$ were assessed. Capsule-positive but colonoscopynegative cases were counted as false positive. Capsule excretion rate, level of bowel preparation, and rate of adverse events also were assessed.

Results. Per-patient CCE-2 sensitivity for polyps $\geq 6 \mathrm{~mm}$ and $\geq 10 \mathrm{~mm}$ was $84 \%$ and $88 \%$, with specificities of $64 \%$ and $95 \%$, respectively. All 3 invasive carcinomas were detected by CCE-2. The capsule excretion rate was $88 \%$ within 10 hours. Overall colon cleanliness for CCE-2 was adequate in $81 \%$ of patients.

Limitations. Not unblinding the CCE-2 results at colonoscopy; heterogenous patient population; nonconsecutive patients.

Conclusion. In this European, multicenter study, CCE-2 appeared to have a high sensitivity for the detection of clinically relevant polypoid lesions, and it might be considered an adequate tool for colorectal imaging.

Abbreviations: CCE-2, second-generation colon capsule endoscopy; PEG, polyethylene glycol. 


\section{INTRODUCTION}

Colorectal cancer represents a major cause of morbidity and mortality in Western countries. ${ }^{1,2}$ Although colorectal cancer prevention based on the identification and removal of precancerous adenomatous polyps at colonoscopy has been highly effective in case-control and randomized studies, ${ }^{3,4}$ colorectal cancer screening uptake is still disappointingly low, especially when compared with the high rate of attendance for breast, cervical, and prostate cancer screening programs. ${ }^{5,6}$ In particular, colonoscopy is usually perceived as an invasive and potentially painful procedure, being also affected by a small but definite risk of major complications, and even mortality. To improve both acceptability and safety, PillCam colon capsule endoscopy (Given Imaging Ltd, Yoqneam, Israel) has been pioneered. Colon capsule endoscopy represents a noninvasive technique that allows exploration of the colon without requiring sedation and air insufflation. When compared with colonoscopy, first-generation colon capsule endoscopy demonstrated safety and feasibility as an imaging test for visualizing the colorectal mucosa. ${ }^{7}$ However, the sensitivity of first-generation colon capsule endoscopy for clinically meaningful lesions - that is, $\geq 6 \mathrm{~mm}$ polyps or massesappeared to be suboptimal as compared with colonoscopy. ${ }^{7}$ For this reason, a secondgeneration colon capsule endoscopy system (CCE-2) has been developed. In particular, the frame rate has been increased from 4 to 35 images per second from the first to the second generation systems, in order to adequately image the mucosa when the capsule is accelerated by peristalsis. The angle of view from each of the two capsule ends also has been increased from $156^{\circ}$ to $172^{\circ}$ for each lens, in order to nearly cover $360^{\circ}$ of the colon surface. In addition, the new data recorder (DR3) provides alerts (visual and audio indications) for procedure activities - such as boost administrations - and it allows realtime viewing on its liquid-crystal diode display. Up to now, CCE-2 has been tested only in one Israeli study, in which sensitivity for polyps $\geq 6 \mathrm{~mm}$ was as high as $89 \%{ }^{8}$

In this European, multicenter, prospective trial, we aimed to assess the accuracy of CCE-2 in detecting patients with polyps $\geq 6 \mathrm{~mm}$ and $\geq 10 \mathrm{~mm}$ or masses, adopting colonoscopy as the reference standard.

\section{PATIENTS AND METHODS}

A total of 8 European sites participated in this prospective study. Recruitment began August 28, 2009 and ended July 7, 2010. Patients (18-80 years of age) who were scheduled to undergo colonoscopy for either known or suspected colonic disease were enrolled in the study. Indications included colorectal cancer screening; personal history of colorectal cancer or adenomatous polyps and at least 3 years since last conventional colonoscopy; clinical symptoms such as rectal bleeding, positive fecal occult blood test, recent change of bowel habits; or positive findings in the colon on GI imaging. Patients were excluded from the study for the following reasons: dysphagia or any swallowing disorder, congestive heart failure, allergy or other known contraindication to the medications used in the study, an increased risk for capsule retention (ie, Crohn's disease, previous abdominal surgeries, ongoing nonsteroidal anti-inflammatory drug use), or cardiac pacemaker or other implanted electromedical device. The study was approved by every local institutional ethics board (MA-201) and met all criteria put forth by the Declaration of Helsinki. All participants signed written informed consent before participation in the study. 


\section{Second-generation colon capsule endoscopy}

All patients enrolled in this study underwent examination with CCE-2 and a conventional colonoscopy procedure on the same or next day.

The CCE-2 capsule is $11.6 \times 31.5 \mathrm{~mm}$ in size, slightly bigger than the previous capsule. It has two imagers with a much wider angle of view, which has been increased to $172^{\circ}$ degrees for each imager, allowing nearly $360^{\circ}$ coverage of the colon. Furthermore, in order to enhance colon visualization and save battery energy, the capsule is equipped with an adaptive frame rate. CCE- 2 captures 35 images per second when in motion and 4 images per second when it is virtually stationary. This advanced system for the control of capsule image rate is the result of bidirectional communication between the CCE-2 and the new data recorder. The capsule battery life is at least 10 hours.

Before the colon capsule endoscopy procedure, patients were instructed to perform the colon preparation procedure, which included 4 senna tablets at bedtime 2 days before examination day, clear liquid diet the day before examination, and $4 \mathrm{~L}$ of polyethylene glycol (PEG), split into two doses (one administered on the evening before the examination and the second on the morning of examination). After capsule ingestion, additional doses of laxatives (sodium phosphate boosters) were administered to facilitate capsule propulsion. The timing of administrating the boosts was indicated by the data recorder (visual and audio indications). Real-time viewing was eventually used by the medical staff to determine the capsule location. If the capsule was not expelled approximately 5 hours after the first boost, a bisacodyl suppository was used. Colon preparation procedure details are listed in the Appendix.

Interpretation of the data was performed by investigators who had prior experience with small bowel capsule endoscopy and who were specifically trained for colon capsule endoscopy. Investigators were blinded to the conventional colonoscopy results. Colon cleanliness was graded by using a 4-point scale (excellent or good [adequate], fair or poor [inadequate]) for each of the following colonic segments ${ }^{9}$ : cecum, right colon, transverse colon, left colon, rectosigmoid colon. An overall colon cleansing grade also was evaluated by using the same grading system. The colon capsule procedure was considered complete when the colon capsule was naturally expelled. When polyps were diagnosed, they were classified with respect to location within the colon, size, and morphology (pedunculated, sessile, flat, and depressed). Polyp size was estimated during capsule video reading by using the polyp size estimation tool included in the RAPID software (Given Imaging Ltd, Yoqneam, Israel). Other lesions such as angiomas, diverticula, inflammation, and hemorrhoids were also described but not considered for statistical analysis.

\section{Colonoscopy}

After the CCE-2 procedure, standard colonoscopy was performed by a physician blinded to the results of CCE-2. Colonoscopy was in most cases performed on the same day (without any additional preparation), after capsule expulsion or at the latest after 10 to 12 hours after capsule ingestion. Because of logistical constraints in two centers, colonoscopy was performed on the next day and an adjunctive bowel cleansing $(2 \mathrm{~L}$ PEG) was indicated in the evening before the procedure. Colonoscopy was performed according to the standard clinical protocol at each participating site by an experienced endoscopist. For each colonoscopy, completeness of the procedure was recorded, and colon cleansing level at the different segments was graded by using the 4-point scale similar to the one used for CCE-2. When polyps were diagnosed, they were classified with respect to morphology (pedunculated, sessile, flat, and depressed), location (colon 
segment and distance from anal verge), size (measured in vivo by using open biopsy forceps with an 8-mm length as reference), and histology.

\section{Statistical methods}

The primary endpoint of the study was to compare the accuracy of CCE- 2 versus colonoscopy for detection of colorectal polyps $\geq 6 \mathrm{~mm}$ as the largest lesions. The same analysis also was performed for the detection of lesions $\geq 10 \mathrm{~mm}$. The analysis was performed according to a per-patient evaluation. Patients without endoscopically confirmed polyps $\geq 6 \mathrm{~mm}$ or $\geq 10 \mathrm{~mm}$ were classified as having a negative result at the reference standard (standard colonoscopy). Patients were considered as having a positive result when at least one polyp $\geq 6 \mathrm{~mm}$ or $\geq 10 \mathrm{~mm}$ was observed at colonoscopy. When two or more polyps were detected in the same patient, the largest was considered for participant classification; accordingly, patients were classified as positive for polyps in the corresponding size range.

CCE-2 results were reported as positive when a polyp $\geq 6 \mathrm{~mm}$ or $\geq 10 \mathrm{~mm}$ was detected, otherwise they were reported as negative. If CCE-2 was positive, and the participant was positive for at least one $\geq 6 \mathrm{~mm}$ or $\geq 10 \mathrm{~mm}$ polyp at colonoscopy that was within $50 \%$ of its reference standard measure at CCE-2, the CCE- 2 result was considered a true positive in that size range. If the CCE-2 result was positive, but the case was classified as negative at colonoscopy, it was considered a false positive.

Sensitivity and specificity along with their exact 95\% confidence intervals (CI) were calculated according to polyp size. No unblinding of colon capsule endoscopy results at colonoscopy was carried out. This was because of the very short interval between CCE2 and colonoscopy procedures, preventing an adequate reading of the CCE-2 examination. Adverse events for both procedures were reported.

For the sample size calculation, considering colonoscopy as the reference standard, colon capsule endoscopy was assumed to have an $84 \%$ sensitivity (with the precision of $\pm 16 \%$ ) (according to the interim analysis of ongoing studies) in detecting patients with polyps equal to or larger than $6 \mathrm{~mm}$. In addition, the prevalence of polyps equal to or larger than $6 \mathrm{~mm}$ was assumed to be $40 \%$ in an enriched population. In order to maintain that hypothesis as well as the type I error $(\alpha)$ of $5 \%$ and power $(=1-\beta)$ of $80 \%$, the required sample size was estimated to be 103. Adding a dropout rate of $13 \%$ resulted in a total study size of 117 patients.

\section{RESULTS}

The 8 participating centers enrolled 117 patients (mean \pm SD age $60 \pm 9$ years; 72 men). Clinical indications for colonoscopy are provided in Table 1. Eight of 117 patients $(6.8 \%)$ were excluded from the efficacy analysis for the following reasons: inability to swallow the capsule ( 1 case), technical failure of the data recorder ( 2 cases), and capsule technical failure (2 cases). In two cases, the capsule remained in the cecum during the entire procedure, and one patient withdrew consent to proceed with the procedure after 7:44 hours. Therefore, a total of 109 patients were included in efficacy analysis.

\section{Colon cleansing level}

The overall cleansing level was adequate in $81 \%$ (95\% CI, $73 \%-88 \%)$ of patients at CCE-2. In detail, it was considered adequate in the cecum in $67 \%$ of patients, in the 
ascending colon in $75 \%$, in the transverse colon in $78 \%$, in the descending colon in $86 \%$, and in the rectum in $63 \%$. The overall cleanliness for colonoscopy was adequate in $92 \%$ of patients.

\section{Colon capsule endoscopy egestion rate}

Overall, $88 \%$ of the capsules were naturally egested within 10 hours $-85 \%$ and $68 \%$ within 8 and 6 hours after ingestion, respectively. In $3(2.6 \%)$ patients, the CCE-2 capsule impacted against a tumor and was retrieved during colonoscopy or surgery. Because of logistical constraints of the study, colonoscopy was performed no later than 8 to 10 hours after capsule ingestion even if the capsule was still active (4 patients, 4\%). Conventional colonoscopy was completed in all but two $(1.7 \%)$ cases (tumor in the descending colon). Both of the procedures (CCE-2 and conventional colonoscopy) identified the tumor and estimated it as $\geq 10 \mathrm{~mm}$.

\section{Colon capsule endoscopy accuracy}

At colonoscopy, a total of 45 patients $(41.3 \%)$ had at least one polyp $\geq 6 \mathrm{~mm}$. Thirty-two patients $(29.3 \%)$ had at least one polyp that was $\geq 10 \mathrm{~mm}$. Per-patient sensitivity of CCE-2 for $\geq 6 \mathrm{~mm}$ and $\geq 10 \mathrm{~mm}$ polyps was $84 \%$ (95\% CI, 74\%-95\%) and $88 \%(95 \%$ CI, 76\%-99\%), respectively (Table 2). All 3 cancers ( 2 in the descending colon and 1 in the sigmoid colon) detected by colonoscopy were also identified by CCE- 2 . Of the 7 false-negative cases at CCE-2, a size mismatch (ie, measured as $<6 \mathrm{~mm}$ at CCE-2) occurred in 3 patients, with a polyp $\geq 6 \mathrm{~mm}$ at colonoscopy ( $6-9 \mathrm{~mm}, 2$ cases; $\geq 10 \mathrm{~mm}$, 1 case), whereas 4 were actually missed by CCE- 2 . When we assessed the 4 lesions, 2 cases were later identified by re-reading as polyps missed by the reader (Fig. 1). In one case, the capsule was retrieved in the ascending colon during colonoscopy while it was still working at 9:44 hours after ingestion. The polyp was distal in the sigmoid colon, and, thus, it was not visualized. The last case should be considered a real falsenegative case (Table 3).

When restricting our analysis only to neoplastic lesions, $39(36 \%)$ and $30(28 \%)$ patients were seen with at least one adenoma $\geq 6 \mathrm{~mm}$ and $\geq 10 \mathrm{~mm}$, respectively. CCE-2 correctly classified 35 and 28 of these patients, corresponding to a detection rate for $\geq 6$ $\mathrm{mm}$ and $\geq 10 \mathrm{~mm}$ neoplasia of $90 \%(95 \% \mathrm{CI}, 80 \%-99 \%)$ and $93 \%(95 \% \mathrm{CI}, 84 \%$ $100 \%$ ), respectively. CCE-2 specificity for detection of polyps $\geq 6 \mathrm{~mm}$ and $\geq 10 \mathrm{~mm}$ was $64 \%$ (95\% CI, 52\%-76\%) and 95\% (95\% CI, 90\%-100\%), respectively. When merging the truepositive and false-positive results, the cumulative CCE-2 positivity rate was $56 \%$ and $29 \%$ for polyps $\geq 6 \mathrm{~mm}$ and $\geq 10 \mathrm{~mm}$, respectively.

When including diminutive (ie, $<5 \mathrm{~mm}$ ) polyps in our analysis, the overall polyp detection rate (regardless of size) at colonoscopy and CCE-2 was $84 \%$ and $81 \%$, respectively.

The low specificity observed in this study for $\geq 6-\mathrm{mm}$ polyps was explained by a substantial rate of false-positive polyps because of size mismatch. As shown in Table 4, $20(80 \%)$ of the 25 false-positive cases at CCE-2 (6-9 mm, 21 cases; $\geq 10 \mathrm{~mm}, 4$ cases) were because of size mismatching (ie, $<6$ or $<10 \mathrm{~mm}$ polyp at colonoscopy measured as $\geq 6$ or $\geq 10 \mathrm{~mm}$ at CCE-2) (Fig. 2). No polyp was detected at colonoscopy in the remaining 5 cases in which CCE-2 detected at least one $\geq 6-\mathrm{mm}$ polyp (Fig. 3 ). The overall colon capsule endoscopy accuracy (mean between sensitivity and specificity) for $\geq 6-\mathrm{mm}$ and $\geq 10-\mathrm{mm}$ lesions appeared to be $76 \%$ and $92 \%$, respectively. 
In addition to polyps or masses, CCE-2 detected other diseases. Colonoscopy detected diverticulosis and erythema/ inflammation in 32 and 11 patients, respectively, and CCE2 identified 24 and 4 of these patients, respectively. Furthermore, CCE-2 detected diverticulosis and erythema/inflammation that were not diagnosed by colonoscopy in an additional 27 and 7 patients, respectively.

In $23 \%$ of cases, the video interpretation took $\leq 30$ minutes, in $47 \%$ of cases $\leq 40$ minutes, and in $71 \%$ of cases $\leq 50$ minutes.

\section{Adverse events}

A total of 8 mild to moderate adverse events were reported in 117 patients $(6.8 \%)$, and these resolved spontaneously within 24 to 48 hours. In 5 of these, adverse events were related to bowel preparation and included vomiting, nausea, and abdominal pain. Two patients experienced fatigue because of the long capsule procedure. One patient experienced severe abdominal pain during conventional colonoscopy.

One patient experienced a severe adverse event not related to colon capsule endoscopy: a colon perforation after polypectomy occurred. The patient was treated endoscopically, was hospitalized, received medical treatment, and the adverse event resolved.

\section{DISCUSSION}

Our prospective, multicenter study showed a sensitivity as high as $84 \%$ and $88 \%$ for $\geq 6$ $\mathrm{mm}$ and $\geq 10$-mm polyps, respectively, when comparing CCE-2 with colonoscopy. These results are well in line with the colon capsule endoscopy-sensitivity values of $89 \%$ and $88 \%$ assessed in the previous Israeli study, ${ }^{8}$ confirming the high colon capsule endoscopy sensitivity for clinically relevant lesions. Of note, the mean age of the patients included in our study - that is, 60 years - is more similar to that of an unselected population referred for colonoscopy, as compared with the previous Israeli study in which only patients aged $<57$ years were included. ${ }^{8}$ The sensitivity of the CCE2 for $\geq 6-\mathrm{mm}$ lesions - consistently superior to $80 \%$ in these first two studies - seems to be higher than the $68 \%$ value estimated in a recent meta-analysis for firstgeneration colon capsule endoscopy, ${ }^{7}$ suggesting the superiority of the new device as compared with the previous one. However, a direct comparison between first-generation and second-generation colon capsule endoscopy was outside the purposes of our analysis, so conclusive statements cannot be made. Moreover, all 3 cases of malignancy were detected by CCE-2 in our study, as was the one case of cancer in the Eliakim et $\mathrm{l}^{8}$ series, whereas a suboptimal sensitivity for cancer was described with first-generation colon capsule endoscopy. ${ }^{7} \mathrm{CCE}-2$ sensitivity would also appear to compare favorably with a similarly noninvasive imaging test, represented by CT colonography, for which a $90 \%$ sensitivity for large polyps was reported. ${ }^{10}$ Presumably, the high sensitivity of CCE-2 in our study as well as in the previous series, ${ }^{8}$ may be a result of the technological improvements of the device, namely the higher frame rate and the larger angle of view of the two lenses. A further reason for the high sensitivity of the CCE-2 may be the relatively high degree of adequate level of bowel preparation achieved in the present series, an intimate association between colon capsule endoscopy sensitivity and level of preparation having already been shown. ${ }^{11}$ The $81 \%$ level of good to excellent preparation shown in our series is well in line with the $78 \%$ reported in the Israeli study as well as with the $78 \%$ reported with the same regimen in a previous study with firstgeneration colon capsule endoscopy. ${ }^{8,12}$ Such a high rate of adequate bowel preparation 
is substantially higher than the median value of $72 \%$ reported in the metaanalysis of the studies with first-generation colon capsule endoscopy ${ }^{7}$ in which such a regimen had not been used. The main improvements of the regimen adopted in the present study are represented by a more balanced splitdose of PEG solution $(2 \mathrm{~L}$ the evening before and 2 $\mathrm{L}$ on the day of capsule ingestion) and a low dose of sodium phosphate boosters. Of note, the low dose of sodium phosphate did not hamper the colon capsule endoscopy excretion rate, an adequate $88 \%$ rate being observed within 10 hours (ie, when study colonoscopy was planned). It also may be speculated that the new feature of data recorder alerts for procedure activities enhanced compliance with the procedure regimen and thus contributed to adequate colon cleansing. It also should be emphasized that only 2 of the 7 false-negative cases were related to a real miss by CCE-2. Indeed, in 3 cases, CCE-2 identified the $\geq 6$-mm polyp, although measuring it as $<6 \mathrm{~mm}$, whereas in two cases a perceptual error by the reader occurred.

An apparently suboptimal specificity of CCE-2 also has been observed in our study, resulting in a low positive predictive value for post-CCE-2 colonoscopy. This would appear quite unexpected when dealing with an endoscopic procedure, such as colon capsule endoscopy, a virtually $100 \%$ specificity for polypoid lesions (ie, irrespectively from histology) being reported with other endoscopic procedures, such as flexible sigmoidoscopy or colonoscopy. ${ }^{13}$ There are at least two main reasons to explain such a result. First, colonoscopy is an imperfect reference standard with a suboptimal sensitivity, especially for 6- to 9 -mm polyps. ${ }^{14,15}$ When considering that in our study, as well as in previous colon capsule endoscopy studies, ${ }^{7,8}$ post-CCE colonoscopy was performed without unblinding of CCE results, it cannot be excluded that apparently false-positive results at CCE were in fact false-negative results at colonoscopy. To overcome this bias, unblinding of CCE-2 results at post-CCE-2 colonoscopy or a different study methodology may be needed. One improvement could be to have only patients with CCE-2-positive results referred to colonoscopy after CCE-2 reading. Second, Table 4 clearly shows that a substantial rate of falsepositive results is related to a misclassification of $<6 \mathrm{~mm}$ polyps at colonoscopy as $\geq 6 \mathrm{~mm}$ at CCE- 2 . When these misclassified polyps are considered as true positive results, specificity for any polyp would be as high as $92 \%$. Although this may question the overall accuracy of colon capsule endoscopy in categorizing lesions as above or below a predefined cut-off, it also should be emphasized that a false-positive result based on a $<6 \mathrm{~mm}$ polyp at post-CCE colonoscopy is much different from a false-positive result with no polyp finding at post$\mathrm{CCE}$ colonoscopy. Considering that the avoidance of polypectomy for $<6-\mathrm{mm}$ lesions is still controversial because of a definite prevalence of advanced neoplasia within these lesions, ${ }^{16}$ the clinical relevance of such size mismatching is likely to be marginal. Moreover, the new polyp size estimation tool that is now embedded in the RAPID software has not been validated, and potential improvements in reading software may be expected to allow a more precise polyp size assessment, reducing the observed mismatch rate. It also could be argued that if we had included in our analysis the diminutive polyps $(<6 \mathrm{~mm}$ ) (their removal after noninvasive diagnosis remains controversial), the post-CCE-2 colonoscopy rate would have been further increased from the $56 \%$ assessed. This would raise some concern regarding the potential cost effectiveness of this approach. However, it is intrinsic in the choice of a noninvasive approach to find a balance between a higher acceptability and a slight reduction of clinical efficacy. 
Our study also confirmed the feasibility and safety of the CCE-2 procedure. A complete visualization of the colo-rectal mucosa was achieved in the vast majority of patients, and no major side effects were reported.

There are limitations to the present analysis. We presented accuracy data for polyps $\geq 6$ $\mathrm{mm}$ with the implicit assumption that post-CCE-2 polypectomy may lead to colorectal cancer prevention. However, such a hypothesis has been challenged by a recent epidemiological study showing no colorectal cancer incidence or mortality reduction after colonoscopy in the right side of the colon. ${ }^{17}$ We adopted colonoscopy as the reference standard, despite that the need for an enhanced reference standard has been clearly shown by previous studies on CT colonography. ${ }^{18}$ Unlike CT colonography studies, ${ }^{10}$ the polyp matching algorithm was based only on polyp size and not location. The accuracy of colon capsule endoscopy in polyp localization needs to be validated. Also in the present study, CCE-2 was tested in an enriched population, resulting in a very high post-CCE-2 colonoscopy rate (ie, total CCE-2 positivity rate). However, it is expected that this rate would be substantially lower in settings with a low prevalence of neoplasia (ie, screening), where noninvasive techniques may be expected to play a major role because of their higher acceptability. Finally, the patient population included in the present series is heterogenous, suggesting that at the moment these results cannot be projected to a screening population.

In this European multicenter study, CCE-2 appeared to be highly sensitive in detecting clinically relevant polypoid lesions, expanding the generalizability of the findings of the previous Israeli study. ${ }^{8}$ When coupling this evidence with the feasibility and safety of colon capsule endoscopy, colon capsule endoscopy may be considered as an adequate tool to visualize the colorectal mucosa. The apparently suboptimal colon capsule endoscopy specificity is likely to be related to the study methodology or polyp size mismatching, with the clinical impact likely to be marginal.

\section{REFERENCES}

1. Ries LA, Wingo PA, Miller DS, et al.The annual reporttothe nation on the status of cancer, 1973-1997, with a special section on colorectal cancer. Cancer 2000;88:2398-424.

2. Ferlay J, Autier P, Boniol M, et al. Estimates of the cancer incidence and mortality in Europe in 2006. Ann Oncol 2007; 18:581-92.

3. Winawer SJ, Zauber AG, Ho MN, et al. Prevention of colorectal cancer by colonoscopic polypectomy. The National Polyp Study Workgroup. N Engl J Med 1993;329:1977-81.

4. Atkin WS, Edwards R, Kralj-Hans I, et al. Once-only flexible sigmoidoscopy screening in prevention of colorectal cancer: a multicentre randomised controlled trial. Lancet 2010;375:1624-33.

5. Segnan N, Senore C, Andreoni B, et al. Comparing attendance and detection rate of colonoscopy with sigmoidoscopy and FIT for colorectal cancer screening. Gastroenterology 2007;132:2304-12.

6. Lisi D, Hassan C, Crespi M; the AMOD Study Group. Participation to colorectal cancer screening with FOBT and colonoscopy: an Italian, multicentre, randomized population study. Dig Liver Dis 2010;42:350-1.

7. Spada C, Hassan C, Marmo R, et al. Meta-analysis shows colon capsule endoscopy is effective in detecting colorectal polyps. Clin Gastroenterol Hepatol 2010;8:516-22. 
8. Eliakim R, Yassin K, Niv Y, et al. Prospective multicenter performance evaluation of the second-generation colon capsule compared with colonoscopy. Endoscopy 2009;41:1026-31.

9. Leighton JA, Rex DK. A grading scale to evaluate colon cleansing for the PillCam COLON capsule: a reliability study. Endoscopy 2011;43:123-7.

10. Johnson CD, Chen MH, Toledano AY, et al. Accuracy of CT colonographyforthe detection of large adenomas and cancers. N Engl J Med 2008;1207-17.

11. Van Gossum A, Munoz-Navas M, Fernandez-Urien I, et al. Capsule endoscopy versus colonoscopy for the detection of polyps and cancer. N Engl J Med 2009;361:264-70.

12. Spada C, Riccioni ME, Hassan C, et al. A new regimen of bowel preparation for PillCam Colon Capsule Endoscopy: a pilot study. Dig Liver Dis 2011;43:300-4.

13. Zauber AG, Lansdorp-Vogelaar I, Knudsen AB, et al. Evaluatingtest strategies for colorectal cancer screening: a decision analysis for the U.S. Preventive Services Task Force. Ann Intern Med 2008;149:659-69.

14. Hixson LJ, Fennerty MB, Sampliner RE, et al. Prospective blinded trial of the colonoscopic miss-rate of large colorectal polyps. Gastrointest Endosc 1991;37:125-7.

15. Rex DK, Cutler CS, Lemmel GT, et al. Colonoscopic miss rates of adenomas determined by back-to-back colonoscopies. Gastroenterology 1997;112:24-8.

16. Lieberman D. Debate: small $(6-9 \mathrm{~mm})$ and diminutive $(1-5 \mathrm{~mm})$ polyps noted on CTC: How should they be managed? Gastrointest Endosc Clin N Am 2010;20:239-43.

17. Baxter NN, Goldwasser MA, Paszat LF, et al. Association of colonoscopy and death from colorectal cancer. Ann Intern Med 2009;150:1-8.

18. Pickhardt PJ, Nugent PA, Mysliwiec PA, et al. Location of adenomas missed by optical colonoscopy. Ann Intern Med 2004;141:352-9.

\section{DISCLOSURE}

C. Spada, C. Hassan, H. Neuhaus, J. Deviere, A. Van Gossum, S. Sacher-Huvelin, J-P Galmiche, and G. Costamagna are speakers for Given Imaging Ltd. J. Deviere, J-P Galmiche, and G. Costamagna have received research grants from Given Imaging Ltd. No other financial relationships relevant to this publication were disclosed.

Current affiliations: Digestive Endoscopy Unit (C.S., C.H., M.E.R., L.P., P. C., G.C.), Catholic University, Rome, Italy; Gastroenterology Department (M.M.-N., C.C., C.P.), University of Navarra Clinic, Pamplona, Spain; Department of Internal Medicine (H.N., J.P.C., R.M.), Evangelisches Krankenhaus, Düsseldorf, Germany; Department of Gastroenterology (J.D., A.V.G., L.A.), Hopital Erasme, Université Libre de Bruxelles, Brussels, Belgium; Department of Gastroenterology and Hepatology (P.F., C.A.W., E.D.), Academic Medical Center, University of Amsterdam, Amsterdam, The Netherlands; Department of Gastroenterology and Hepatology (E.C., S.S.-H., J.-P.G.), University Hospital, Nantes, France; Department of Internal Medicine and Digestive Pathology (G.G., M.D., M.F.), Hopitaux de Brabois, University Hospital of Nancy, Vandoeuvre les Nancy, France; Endoscopy Unit (E.T., A.N., G.W.J.), Skåne University Hospital, Malmö, Sweden.

Reprint requests: Cristiano Spada, MD, Digestive Endoscopy Unit, Catholic University, Largo F. Vito 1, 00168 Rome, Italy. E-mail: cristianospada@gmail.com. 


\begin{tabular}{|l|c|}
\hline \multicolumn{2}{|c|}{ Table 1. Indication for colonoscopy* } \\
\hline Indication, no. (\%) & $52(44)$ \\
\hline Personal history of polyps/positive findings & $27(23)$ \\
\hline Recent change in bowel habits & $25(21)$ \\
\hline Colorectal cancer screening & $23(20)$ \\
\hline Rectal bleeding/hematochezia & $18(15)$ \\
\hline Abdominal pain & $7(6)$ \\
\hline Positive fecal occult blood test & $\begin{array}{l}\text { *Some patients were enrolled because of more than one } \\
\text { indication. }\end{array}$ \\
\hline
\end{tabular}

\begin{tabular}{|c|c|c|c|}
\hline & Colonoscopy & PillC & lon 2 \\
\hline Polyp size, mm & $\begin{array}{c}\text { Prevalence, } \\
\text { no. (\%) }\end{array}$ & $\begin{array}{c}\text { Sensitivity,\% } \\
\text { (95\% CI) }\end{array}$ & $\begin{array}{c}\text { Specificity,\% } \\
\text { (95\% CI) }\end{array}$ \\
\hline$\geq 6 \mathrm{~mm}$ & $45(41)$ & $84(74-95)$ & $64(52-76)$ \\
\hline$\geq 10 \mathrm{~mm}$ & $32(29)$ & $88(76-99)$ & $95(90-100)$ \\
\hline
\end{tabular}

\begin{tabular}{|l|c|c|}
\hline \multicolumn{2}{|c|}{$\begin{array}{r}\text { Table 3. Real false-negative lesions } \geq 6 \mathrm{~mm} \text { (excluding those related to size } \\
\text { mismatching between CCE-2 and colonoscopy) }\end{array}$} \\
\hline Polyp size by colonoscopy & Location & Comment \\
\hline $80 \mathrm{~mm}$ & Cecum & $\begin{array}{c}\text { Independent, unblinded } \\
\text { review detected the polyp }\end{array}$ \\
\hline $12 \mathrm{~mm}$ & Ascending & $\begin{array}{c}\text { Independent, unblinded } \\
\text { review detected the polyp }\end{array}$ \\
\hline $20 \mathrm{~mm}$ & Descending-sigmoid & $\begin{array}{c}\text { CCE-2 was retrieved in the } \\
\text { ascending colon during } \\
\text { colonoscopy 9:44 hours } \\
\text { after ingestion. The polyp } \\
\text { was in the sigmoid colon } \\
\text { and, thus, was not } \\
\text { visualized }\end{array}$ \\
\hline $7 \mathrm{~mm}$ & Ascending & \begin{tabular}{c} 
False negative \\
\hline CCE-2, PillCam Colon 2 second-generation capsule endoscopy system.
\end{tabular} \\
\hline
\end{tabular}




\begin{tabular}{|c|c|c|}
\hline \multicolumn{3}{|c|}{ Table 4. False-positive lesions $\geq 6 \mathrm{~mm}$} \\
\hline $\begin{array}{c}\text { Polyp size by } \\
\text { colonoscopy, mm }\end{array}$ & $\begin{array}{l}\text { Polyp size by } \\
\text { capsule, mm }\end{array}$ & Comment \\
\hline- & 9 & False positive \\
\hline- & 9 & False positive \\
\hline- & 6 & False positive \\
\hline- & 7 & False positive \\
\hline- & 8 & False positive \\
\hline 4 & 7 & Size mismatch \\
\hline 2 & 8 & Size mismatch \\
\hline 3 & 6 & Size mismatch \\
\hline 3 & 7 & Size mismatch \\
\hline 3 & 6 & Size mismatch \\
\hline 5 & 6 & Size mismatch \\
\hline 5 & 6 & Size mismatch \\
\hline 4 & 7 & Size mismatch \\
\hline 3 & 6 & Size mismatch \\
\hline 3 & 7 & Size mismatch \\
\hline 5 & 6 & Size mismatch \\
\hline 5 & 6 & Size mismatch \\
\hline 3 & 7 & Size mismatch \\
\hline 4 & 6 & Size mismatch \\
\hline 4 & 6 & Size mismatch \\
\hline 4 & 6 & Size mismatch \\
\hline 4 & 12 & Size mismatch \\
\hline 5 & 12 & Size mismatch \\
\hline 8 & 10 & Size mismatch* \\
\hline 7 & 10 & Size mismatch* \\
\hline \multicolumn{3}{|c|}{$*$ Only at $>10$ mm cut-off. } \\
\hline
\end{tabular}


Figure 1. False-negative cases: two cases of lesions missed by PillCam Colon 2 capsule endoscopy (CCE-2). A, An 80-mm polyp visualized by colonoscopy in the cecum. C, A $12-\mathrm{mm}$ polyp visualized by colonoscopy in the ascending colon. Polyps missed by the investigators at CCE-2 were later identified by an unblinded reviewer not associated with the study $(\mathbf{B}, \mathbf{D})$.
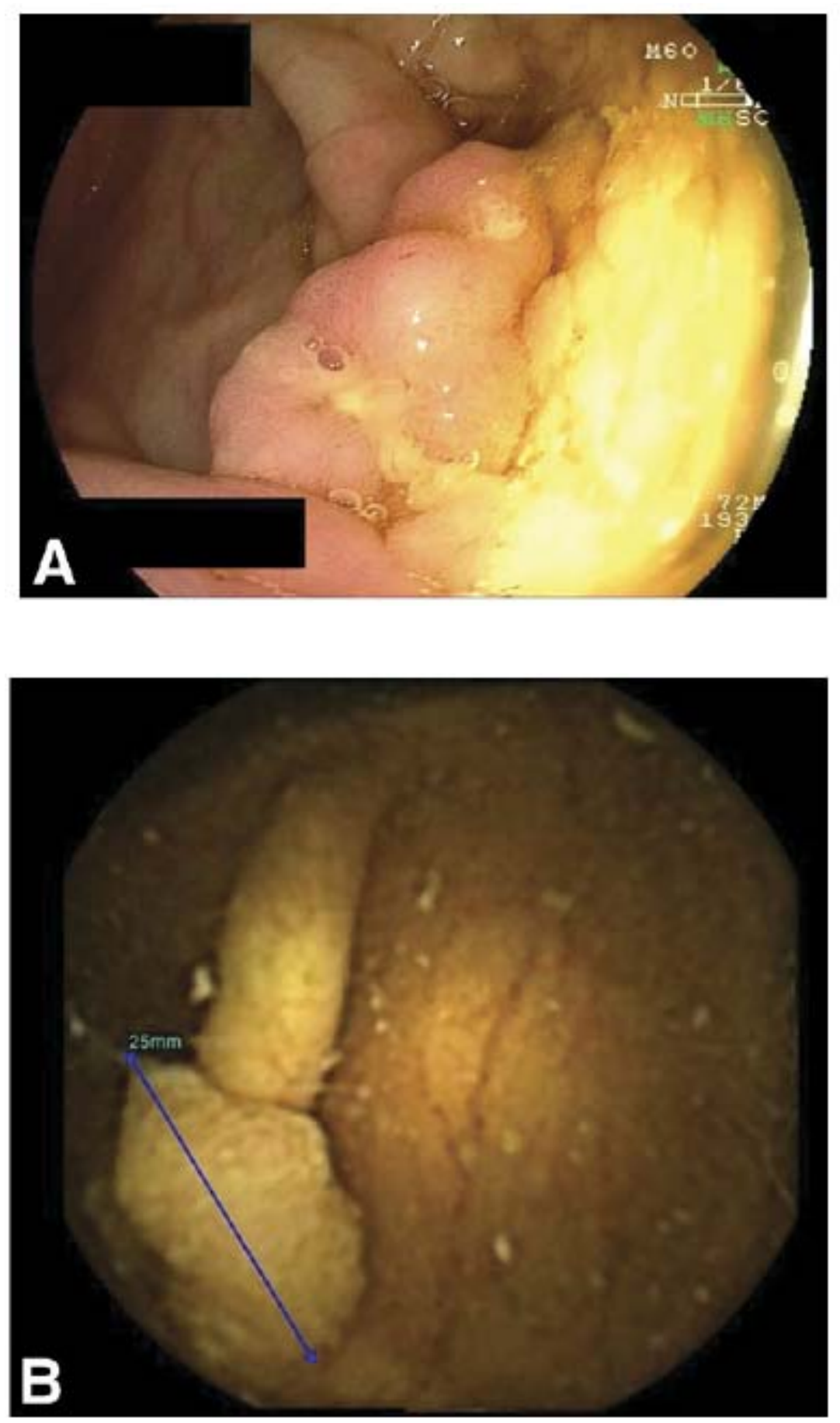

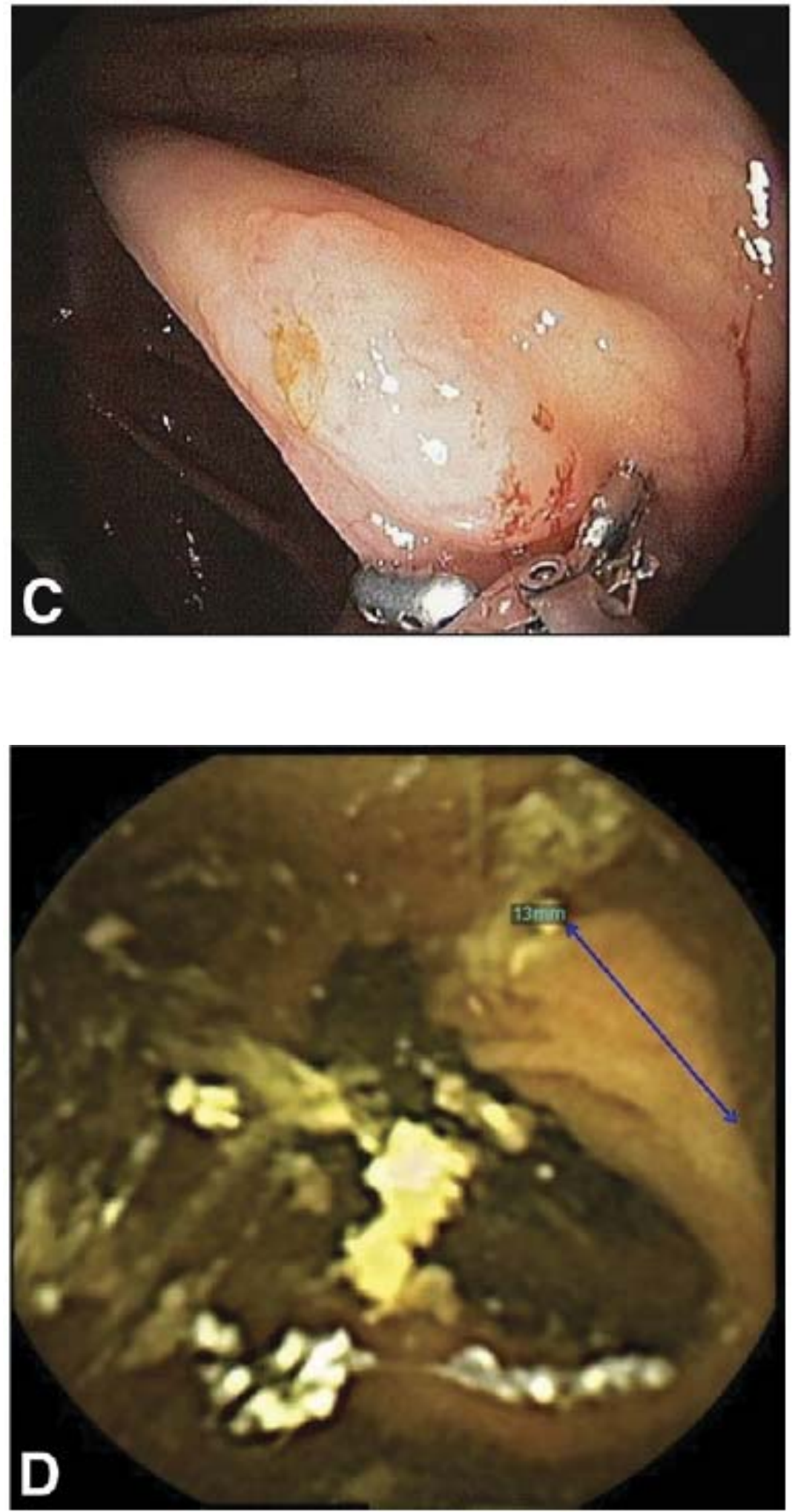
Figure 2. False-positive cases because of size mismatch. A, PillCam Colon 2 capsule endoscopy (CCE-2) identified a 6-mm polyp that at colonoscopy was measured as 5 $\mathrm{mm}(\mathbf{B})$. C, A 10-mm polyp by CCE-2: the size estimation at colonoscopy was $8 \mathrm{~mm}$ (D).
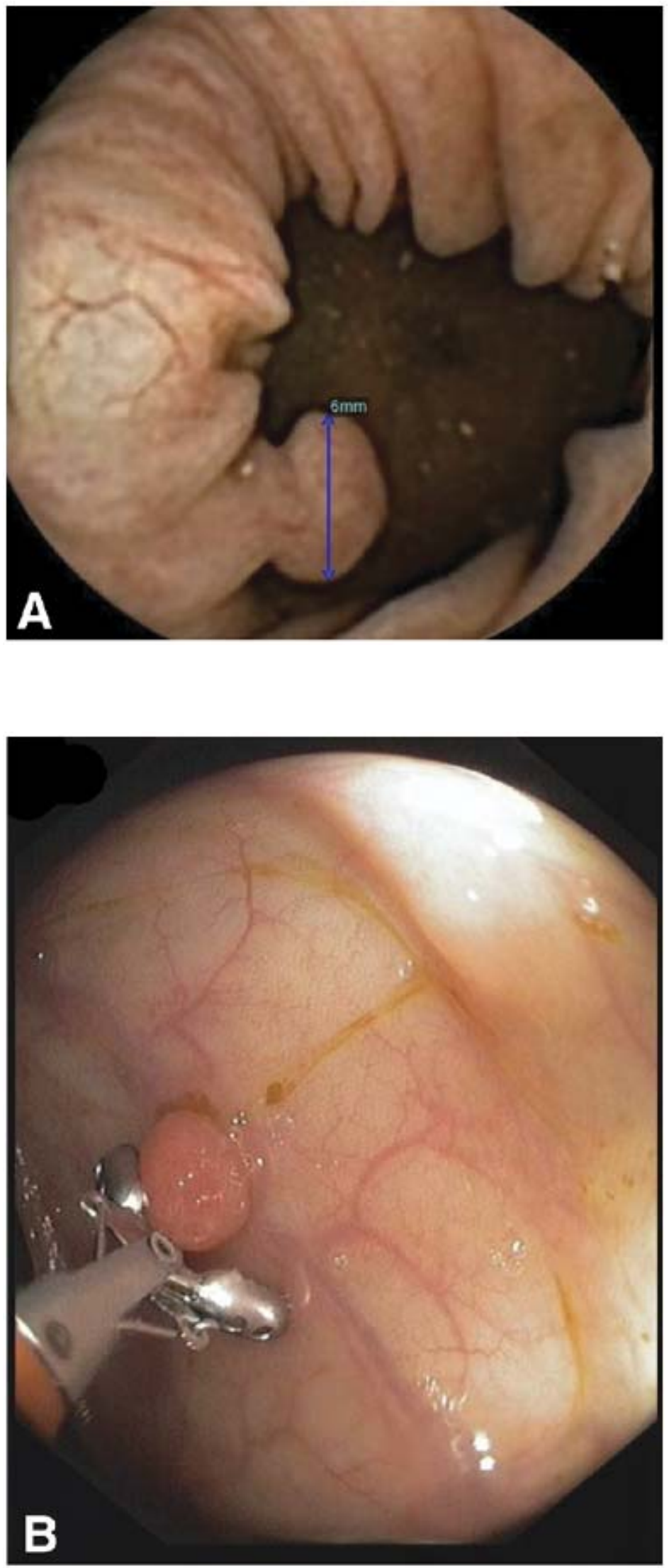

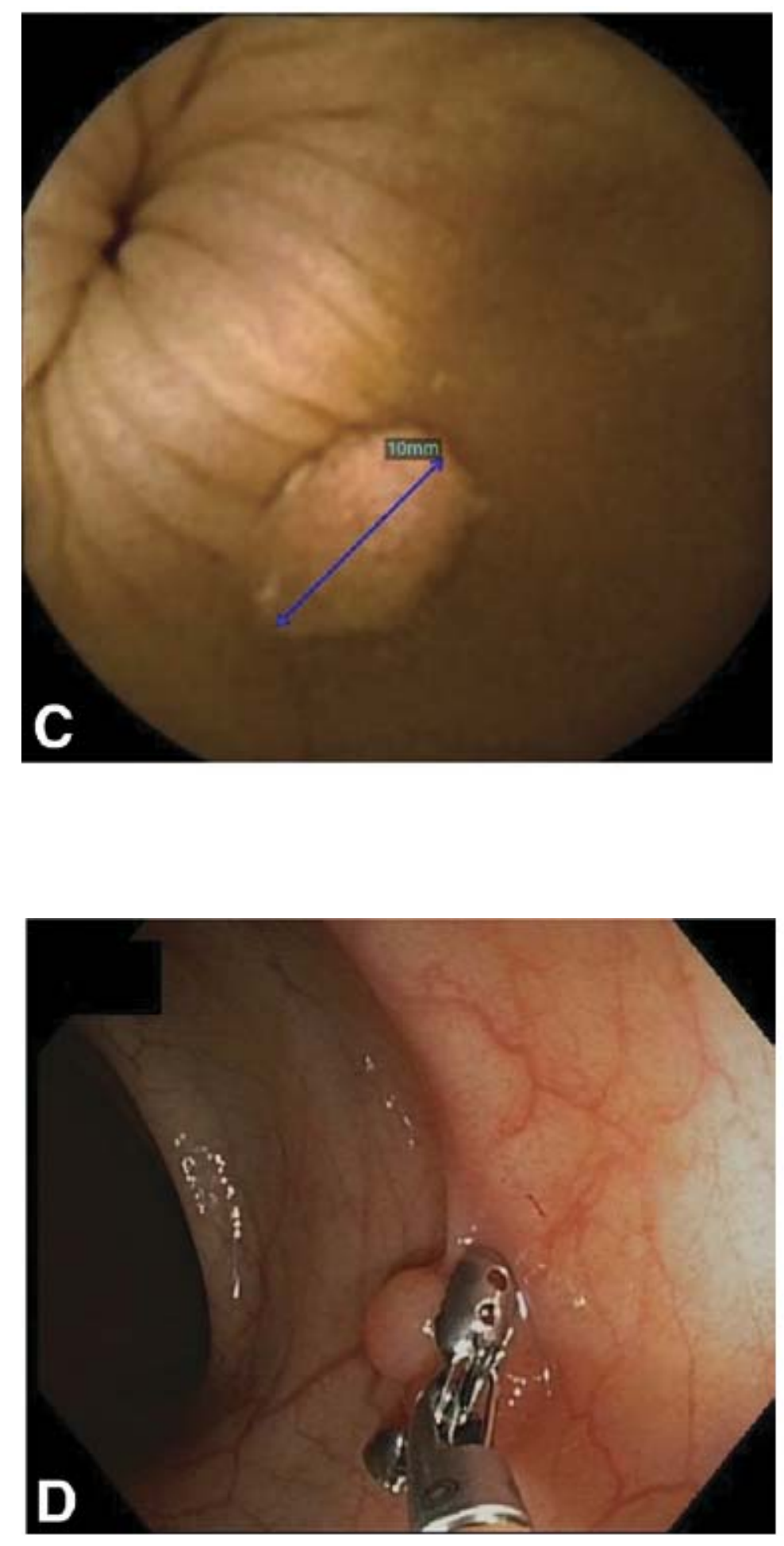
Figure 3. False-positive cases (polyps missed by colonoscopy). Images of 3 falsepositive cases: 9-mm polyp (A), 7-mm polyp (B), and 8-mm polyp (C). PillCam Colon 2 capsule endoscopy identified these polyps that were missed by colonoscopy.
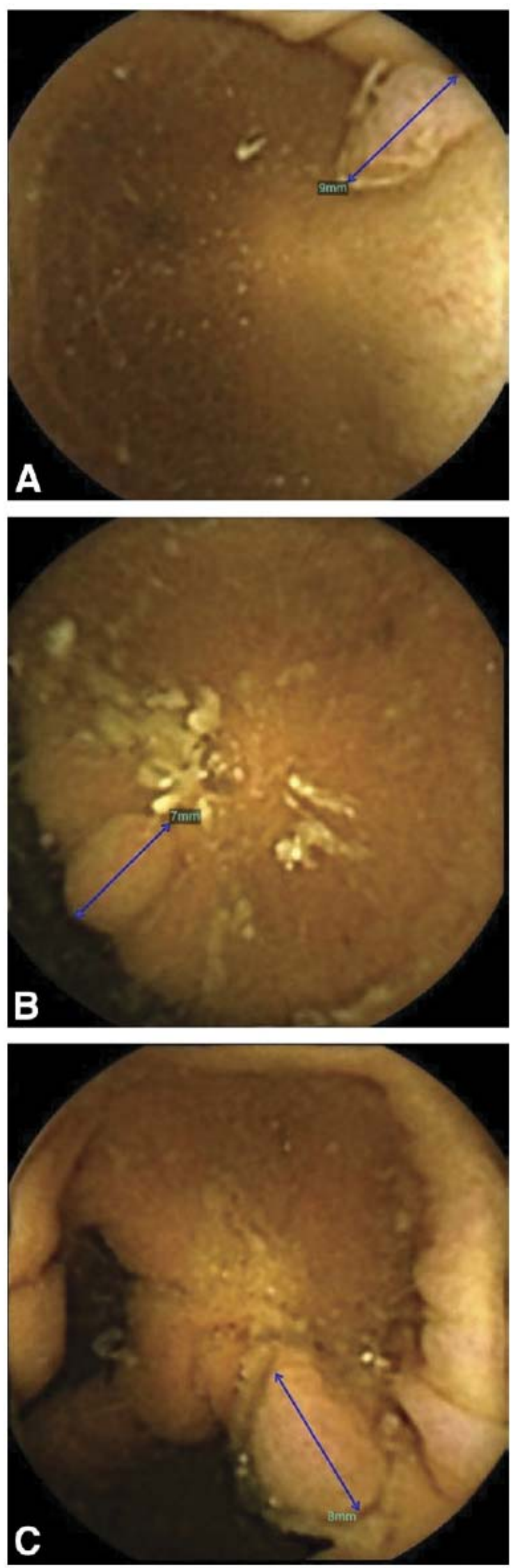
APPENDIX: PILLCAM COLON 2 PREPARATION REGIMEN

\begin{tabular}{|c|c|c|}
\hline Day & Timing & Procedure \\
\hline \multirow[t]{2}{*}{ Day 2} & All day & $\begin{array}{l}\text { At least } 10 \text { glasses of } \\
\text { water }\end{array}$ \\
\hline & Bedtime & $\begin{array}{l}4 \text { senna tablets (12 mg } \\
\text { each) }\end{array}$ \\
\hline \multirow[t]{2}{*}{ Day 1} & All day & Clear liquid diet \\
\hline & Evening & $2 \mathrm{~L}$ PEG \\
\hline \multirow[t]{5}{*}{ Examination day } & Morning & $2 \mathrm{~L} \mathrm{PEG}$ \\
\hline & About 10 AM & Capsule ingestion* \\
\hline & $\begin{array}{l}\text { First boost Upon small } \\
\text { bowel detection }\end{array}$ & $\begin{array}{l}30 \mathrm{~mL} \text { sodium phosphate } \\
\& 1 \mathrm{~L} \text { water }\end{array}$ \\
\hline & $\begin{array}{l}\text { Second boost } 3 \mathrm{~h} \text { after } \\
\text { first boost }\end{array}$ & $\begin{array}{l}25 \mathrm{~mL} \text { sodium phosphate } \\
\& 0.5 \mathrm{~L} \text { water }\end{array}$ \\
\hline & $\begin{array}{l}\text { Suppository } 2 \mathrm{~h} \text { after } \\
\text { second boost }\end{array}$ & $10 \mathrm{mg}$ bisacodyl \\
\hline
\end{tabular}

